\title{
The Relationship between Optimism and Happiness of Physical Education Teachers' Candidates: The Mediator Role of Life Satisfaction
}

\author{
Nazmi Bayköse ${ }^{1 \rtimes}$ \\ Barbaros Serdar Erdoğan² \\ ${ }^{\prime}$ Faculty of Sport Sciences, Akdeniz University, Antalya, Turkey. \\ Email:nazmibaykose@gmail.com \\ ${ }^{2}$ Faculty of Sport Sciences, Mehmet Akif Ersoy University, Burdur, Turkey.
}

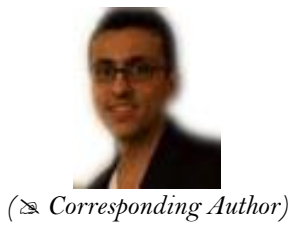

\section{Abstract}

The aim of this study is to examine the mediating role of life satisfaction in the relationship between optimism and happiness levels of physical education teacher candidates. The research group consists of 278 physical education teacher candidates who were trained in the formation education program opened at Akdeniz University in the 2018-2019 academic year. Optimism Scale, Happiness Scale and Life Satisfaction Scale were used to collect research data. In the process of analyzing the data, Pearson correlation analysis was used first to determine the relationships of variables with each other, and PROCESS macro regression analysis was used to determine the mediating effect of life satisfaction between optimism and happiness. As a result, it can be said that life satisfaction has a mediating role in the relationship between optimism and happiness levels of physical education teacher candidates. In line with this information, considering that life satisfaction is an important psychological factor in physical education teacher candidates, it is extremely important to keep the life satisfaction levels of physical education teacher candidates, who have a primary effect on the healthy upbringing of future generations. In this context, it is recommended that relevant rule makers or managers who want to increase the quality and quality of education take this information into consideration.

Keywords: Teacher candidate, Life satisfaction, Optimism, Happiness, Physical education, Sport.

Citation | Nazmi Bayköse; Barbaros Serdar Erdoğan (2021). The Relationship between Optimism and Happiness of Physical Education Teachers' Candidates: The Mediator Role of Life Satisfaction. Asian Journal of Education and Training, 7(1): 25-29. History:

Received: 9 November 2020

7 December

Accepted: 28 December

Published: 18 Jactiber 2020

Licensed: This work is licensed under a Creative Common Attribution 3.0 License $(\mathrm{cc}) \boldsymbol{P}$

Publisher: Asian Online Journal Publishing Group
Acknowledgement: Both authors contributed to the conception and design of the study.

Funding: This study received no specific financial support

Competing Interests: The authors declare that they have no conflict of interests.

Transparency: The authors confirm that the manuscript is an honest, accurate, and transparent account of the study was reported; that no vital features of the study have been omitted; and that any discrepancies from the features of the study have been omitted
study as planned have been explained.

Ethical: This study follows all ethical practices during writing.

\section{Contents}

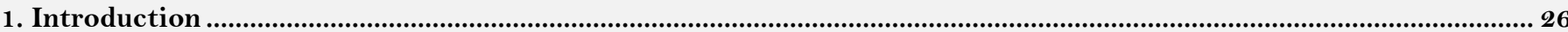

2. Method

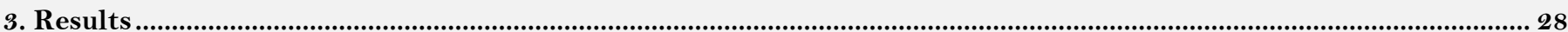

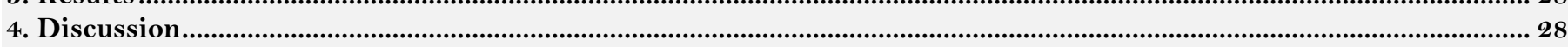

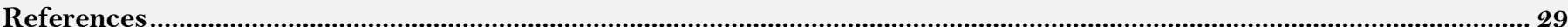




\section{Contribution of this paper to the literature}

This study contributes to existing literature by examining the mediating role of life satisfaction in the relationship between optimism and happiness levels of physical education teacher candidates.

\section{Introduction}

Today, educational activities have gained speed with the contribution of developing technological opportunities and continue to increase rapidly. Depending on this development, research in the field of education and training focuses on a wide variety of problems and includes all stakeholders of education and training. Perhaps one of the most important issues regarding this education problematic is the psychological qualities of teachers. In this study, it focuses on the qualifications of pre-service teachers who will do teaching as a profession in the following years. Teachers are individuals who have a high sense of responsibility and have the characteristic of being a role and model for the students they will carry out education and training activities. It is extremely important for these individuals to have a positive psychological mood, to be individuals who are generally satisfied with their life, who can show an optimistic approach to problems or problems, and who can be satisfied with their lives. It is extremely likely that teachers with these positive qualities will raise students they are role models in this mood.

When we look at the psychology literature, it can be said that there are two known approaches, which are basic approaches, which defend the view that human beings are essentially negative psychological structures (Human is essentially bad: Psychoanalytic approach) or that human is inherently neutral (human is neither good nor bad: behavioral approach). Of course, today, these two basic approaches have been left behind, and in the following years, it has been stated that it is not enough to focus on psychologically abnormal behaviors or negative psychotic processes in line with the basic view of the humanistic approach. In line with this view, based on the positive aspects of human, it has been suggested that there is goodness and a positive psychological structure in human nature. At this point, the positive psychology view caused the positive psychology trend to begin as a trend. Happiness, optimism and life satisfaction, which are the subject of our research, are among these issues.

With existence, happiness has become a desired and desired feeling. Happiness, which is the basic common purpose of individuals, has become a common goal of societies. Happiness is a versatile concept that includes many factors individually. It is the current concept of positive psychology that should be examined both psychologically and physiologically.

The concept of happiness in general definition in the literature is "joy and happiness that comes with the individual attaining his desires, goals, desires." It is defined as. In the philosophical literature, on the other hand, the concept of happiness is expressed factually as "the ultimate goal of human actions, the main goal that needs nothing but itself". In the psychology literature, on the other hand, they are "positive affects." It is defined as. A happy individual is psychologically optimistic, peaceful, happy, compatible with himself and his environment, and at the same time lively and energetic in the context of the body (Tarhan, 2005).

Having a profitable positive perspective on events and facts also enables coping with problems. To look at it from another angle, individuals who approach events and phenomena from a negative perspective are extremely unlikely to solve these problems. Specific to such situations, optimism tendency has an important role sole (Balcı \& Yllmaz, 2002). Optimism refers to having a positive attitude towards the events that confront them, unlike a fixed event. In line with these thoughts, it stands out as an outcome of the self-efficacy belief of the individual (Gillham \& Reivich, 2004).

When the personal characteristics of individuals with a high level of optimism are examined, it is known that these individuals are practice-oriented. These people tend to have an active role in solving the problem, rather than waiting for the solution to be solved during the time when they encounter any problem (Fellman, 2000). Optimistic individuals do not allow their thoughts to be shaped with negativity, they try to evaluate events and facts in a positive framework by thinking within the framework of logic and focusing on the positive (McGinnis, 1998). Since these mental processes will reduce the possibility of conflict with the optimistic individuals themselves or with the individuals around them, these individuals will have a more harmonious, happy and peaceful life (Kasatura, 1998).

The concept of satisfaction is defined as "meeting expectations, needs, requests and wishes" in the relevant literature. Life satisfaction is defined as "the final result a person obtains by comparing his expectations (what he wants) with his possibilities (what he / she has)." (Vara, 1999). Life satisfaction includes the tendency to change the level of satisfaction that the individual will have at the moment and in the future, and the subjective views of the people he / she interacts with about his / her life. Some areas related to life satisfaction are described by Diener, Suh, Lucas, and Smith (1999), close environment, leisure time, self-worth, material opportunity, moral value, job, relationship, etc. covers concepts. As a profession, teaching is a profession that interacts with different psychological dynamics and requires constant interaction with groups of people with different profiles (student profiles, parent profiles, manager profiles and colleague profiles). It is for these reasons that, as a social phenomenon, teachers have a feature and quality that can affect all the profiles they interact with. From this point of view, the most effective theme that teachers interact with is with their students. There is no doubt that the students whose current psychological states / moods that teachers have in psychological sense will be the primary influence. In this direction, it is extremely important for teachers to be mentally healthy and fit.

In this study, the positive psychological characteristics (optimism and happiness) of teacher candidates who will exercise their teaching rights, which have become popular in the coming years, and how effective their satisfaction with their lives can be examined in this psychological structure. In this context, it was determined as the investigation of the mediating role of life satisfaction in the relationship between optimism and happiness levels of prospective teachers.

\section{Method}

\subsection{Research Model}

This study is a relational survey designed to examine the life satisfaction levels of prospective teachers as a mediator in the relationship between continuous optimism and happiness. Karasar (2013) defined relational 
scanning models as research models that aim to determine the existence and degree of change between two or more variables. The relational scanning model is defined by Büyüköztürk, Kılıç Çakmak, Akgün, Karadeniz, and Demirel (2008) as a screening method that includes correlational and causal methods and investigates relationships and connections. Within the scope of this model, the role of life satisfaction between the levels of continuous optimism and happiness of individuals who exercise for recreational purposes will be examined. The hypothesis model determined within the scope of the research purpose is given below (Figure 1).

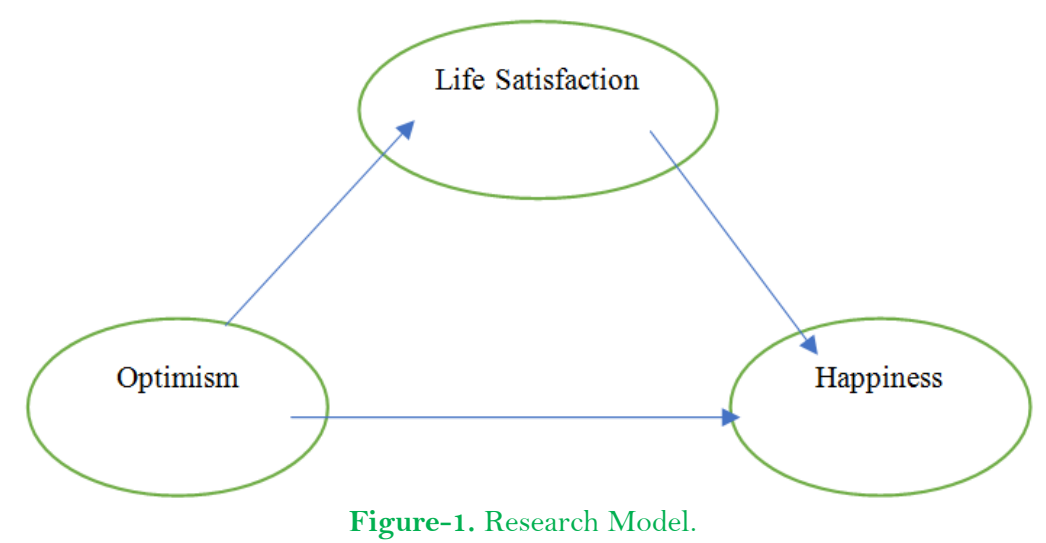

\subsection{Research Group}

The research group consists of 278 (Age Mean $_{2} 23.83+3.187$ ) physical education teacher candidates who received training in the formation training program opened at Akdeniz University in the 2018-2019 academic year see Table 1. All the physical education teacher candidates participating in the study first filled out the voluntary participation form created by the researchers, and then filled out the data collection tools determined within the scope of the research.

\begin{tabular}{l|c|c|c} 
Table-1. Demographic characteristics and information of the participants. \\
\hline Gender Variable & & $\mathbf{n}$ & $\mathbf{\%}$ \\
\hline & Women & 159 & 57,2 \\
\hline & Men & 119 & 43,8 \\
\hline
\end{tabular}

\subsection{Collection of Data}

Optimism Scale, Happiness Scale and Life Satisfaction Scale were used to collect research data. During the preparation process of the collected data, it was observed that 28 exercise participants participated in the research completed the scales used in the data collection process incompletely, and the analyzes were evaluated in a sample of 278 physical education teacher candidates.

\subsubsection{Optimism Scale}

The optimism scale was developed by Scheier and Carver (1985) and adapted to Turkish culture by Aydin and Tezer (1991). The optimism scale was developed in the 5-point Likert type and it measures in a single subdimension of 12 items. The reliability coefficient of the scale is .83.

\subsubsection{Happiness Scale}

Oxford Happiness Scale was developed by Hills and Argyle (2002) and adapted to Turkish culture by Doğan and ÇÖTOK (2011). The psychological resilience scale was developed in 5-point Likert type and it measures in a single sub-dimension of 7 items. The reliability coefficient of the scale is .96.

\subsubsection{Life Satisfaction Scale}

Psychological resilience scale Diener, Emmons, Larsen, and Griffin (1985) and adapted to Turkish culture by Köker (1991). The psychological resilience scale was developed in 7-point Likert type and it measures in a single sub-dimension of 5 items. The reliability coefficient of the scale is .88 .

\subsubsection{Personal Information form}

A personal information form consisting of three questions was used to determine the demographic characteristics of teacher candidates participating in the study. With the personal information form, it was aimed to determine the graduation status, gender and age groups of the teacher candidates.

\subsection{Data Analysis}

Before data analysis, the skewness and kurtosis values of the variables were examined in order to evaluate the suitability of the data set for analysis. In the examination, it was seen that the skewness and kurtosis values of all variables were between +1 and -1 see Table 2 . In this context, it can be said that the data have a normal distribution (George \& Mallery, 2010). In the process of analyzing the data, Pearson correlation analysis was used first to determine the relationships of variables with each other, and PROCESS macro regression analysis was used to determine the mediating effect of life satisfaction between optimism and happiness. The analyzes were performed at $95 \%$ confidence interval. Sobel $z$ test was used to test whether the mediation was significant or not. SPSS 22.00 package program was used for the analysis of the research. 
Table-2. Normality analysis of research variables.

\begin{tabular}{l|c|c|c}
\hline & $\bar{X} \pm$ SS & Skewness & Kurtosis \\
\hline Optimism & $3,25 \pm 0,61$ &, 244 &,- 258 \\
\hline Happiness & $3,89 \pm 0,66$ &, 980 &, 852 \\
\hline Life Satisfaction & $4,79 \pm 0,67$ &, 735 &,- 370 \\
\hline Note: ${ }^{*} \mathrm{p}<0.05{ }^{*}{ }^{*} \mathrm{p}<0,01$.
\end{tabular}

\section{Results}

Table-3. Independent Sample t-test Results of the Physical Education Teacher Candidates' Optimism, Happiness and Life Satisfaction Scores According to Their Gender.

\begin{tabular}{|c|c|c|c|c|c|c|}
\hline & \multicolumn{2}{|c|}{ Women } & \multicolumn{2}{|c|}{ Men } & \multirow[b]{2}{*}{$\mathrm{t}$} & \multirow[b]{2}{*}{ p } \\
\hline & $\mathbf{n}$ & $\bar{X} \pm \mathbf{S S}$ & $\mathbf{n}$ & $\bar{X}_{ \pm \mathbf{S S}}$ & & \\
\hline Optimism & 159 & $3,04 \pm 0,63$ & 119 & $3,10 \pm 0,60$ & $-1,124$ &, 262 \\
\hline Happiness & 159 & $3,79 \pm 0,52$ & 119 & $3,99 \pm 0,72$ & $-3,757$ &, $000^{*} *$ \\
\hline Life Satisfaction & 159 & $4,75 \pm 0,56$ & 119 & $4,82 \pm 0,72$ & $-1,313$ &, 190 \\
\hline
\end{tabular}

Note: *p $<0.05$,** $<0,01$

Table 3 shows the analysis of the difference between men and women. It was found that there was no statistically significant difference between the genders in terms of optimism and life satisfaction levels $(p>0.05)$. It was determined that there is a statistically significant difference between the genders at the level of happiness ( $p$ $<0.01$ ). Accordingly, the values of physical education teacher candidates are lower than men in terms of the happiness level variable.

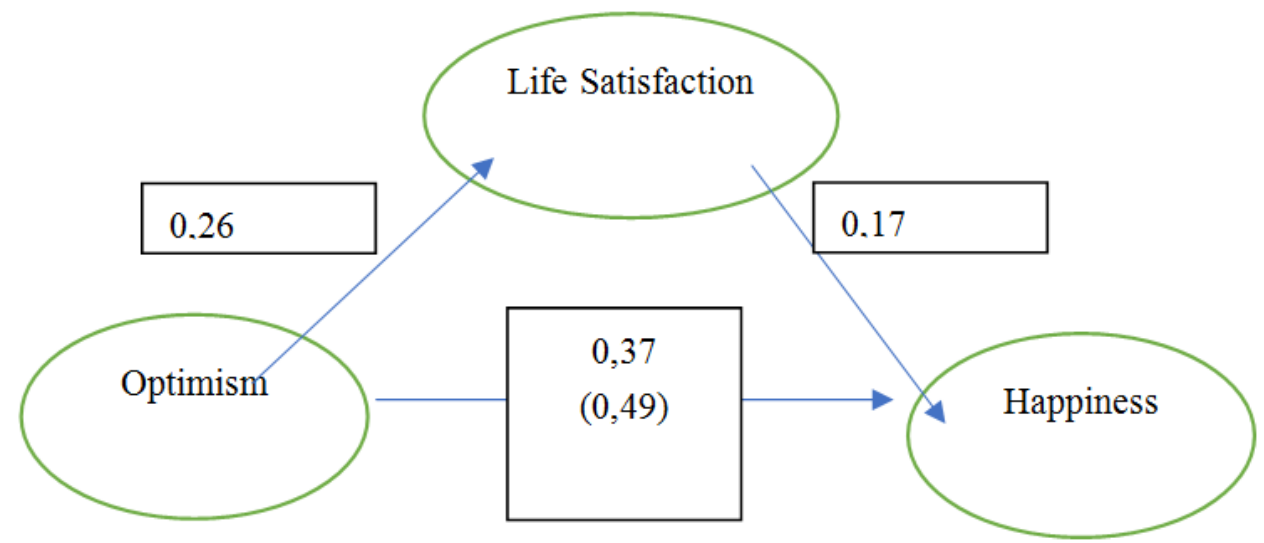

Figure-2. Mediator role of life satisfaction in the relationship between optimism and happiness.

When Figure 2 is examined the significant relationship between optimism and happiness $(\beta=.37)$ increases with the addition of life satisfaction variable $(\beta=.49)$ to the model. The relationship between benevolence and happiness $(\beta=.37)$ and happiness and life satisfaction $(\beta=.17)$ was examined. According to the results of the Sobel test conducted to test the significance of this increase, it was found that the increase was not significant $(Z=.97$, $\mathrm{p}>.05)$ and life satisfaction was the mediator variable in the relationship between optimism and happiness.

\section{Discussion}

In this study, the mediating role of life satisfaction in physical education teacher candidates at the level of happiness was examined. In addition to the optimism of teachers, who have a very important role in the upbringing of children of the future generations, happiness and life satisfaction should be emphasized in terms of the quality of education.

In line with this purpose, the research group consists of 278 physical education teacher candidates who received training in the formation training program opened at Akdeniz University in the 2018-2019 academic year. All teacher candidates participating in the study first filled out the voluntary participation form created by the researchers, and then filled out the data collection tools determined within the scope of the research. The levels of optimism, happiness and life satisfaction of physical education teacher candidates who voluntarily participated in the study were determined.

In line with the findings, it was determined that there is a positive relationship between optimism and happiness. When the relevant literature was examined in connection with this relationship, results supporting the findings of this study were found in different sample groups. In a study in the related literature and conducted by Sahin (2015), a positive, significant and moderate relationship between happiness and optimism was found. In another study, Sapmaz and Doğan (2012) found in their study that optimism is positively associated with happiness. In another study conducted by Seligman and Pawelski (2003), it was concluded that optimistic individuals could produce more comfortable solutions to the problems they encountered and were happier than non-optimistic individuals. There are other studies (Cummins \& Nistico, 2002; Ryan \& Deci, 2001) showing that optimism predicts happiness.

Another result obtained based on the research findings is that the positive relationship between optimism and happiness is mediated by life satisfaction and the effect of optimism on happiness level increases through life satisfaction. In other words, life satisfaction mediates optimism, which is the determinant of happiness, with a positive contribution. In line with this information, the increase in the level of satisfaction with the life of physical education teachers with increased optimism may directly reflect on their happiness level. When the relevant literature was examined, results in parallel with our findings of this study were obtained in sample groups different 
from our sample group. One of these studies is the research conducted by Gülcan (2014). In the study conducted by Gülcan (2014), the effect of optimism on happiness and life satisfaction in young adults was examined. According to the research findings, optimism was found to be positively associated with life satisfaction and happiness. In line with this information, it can be said that the findings obtained by Gülcan (2014) support our research. At the same time, Ho, Cheung, and Cheung (2010) research indicates that optimism predicts subjective well-being. Considering that subjective well-being is a combination of positive mood and life satisfaction, it can be accepted as additional evidence that optimism is related to life satisfaction and happiness.

This research was conducted within the scope of physical education teacher candidates. The high physical activity levels of physical education teacher candidates may have been effective in this model. Accordingly, as stated in the relevant literature, Wike (2015) reported that the psychological well-being levels of the participants in the study were high in the sample of young people participating in physical activity. Özkatar Kaya, Sarıtaş, Yıldız, and Kaya (2018) stated that physical activity has a positive effect on the life satisfaction of individuals as well as the quality of life. In parallel with our findings, Güllü and Ciftçi (2016) revealed in their study that the quality of life of adults who do physical activity is high. Based on these findings, a similar study can be designed in which physical activity levels are also measured in future studies. Because one of the most important limitations of our study, the physical activity level measurement, which is highly effective in psychological terms, was not made within the scope of our research.

As a result, it can be said that life satisfaction has a mediating role in the relationship between optimism and happiness levels of physical education teacher candidates. In line with this information, considering that life satisfaction is an important psychological factor in physical education teacher candidates, it is extremely important to keep the life satisfaction levels of physical education teacher candidates, who have a primary effect on the healthy upbringing of future generations. In this context, it is recommended that relevant rule makers or managers who want to increase the quality and quality of education take this information into consideration.

\section{References}

Aydin, G., \& Tezer, E. (1991). The relationship between optimism, health problems and academic success. Turkish Journal of Psychology, 26(7), $2-9$.

Balcı, S., \& Yılmaz, M. (2002). Validity and reliability study of optimism scale. 19 Mayzs University Journal of Educational Sciences, 14(1), 54-60. Büyüköztürk, Ş., Kılıç Çakmak, E., Akgün, Ö. E., Karadeniz, Ş., \& Demirel, F. (2008). Scientific research methods. Ankara: Pegem Academy Publications.

Cummins, R. A., \& Nistico, H. (2002). Maintaining life satisfaction: The role of positive cognitive bias. Journal of Happiness Studies, 3(1), 3769.

Diener, E., Suh, E. M., Lucas, R. E., \& Smith, H. L. (1999). Subjective well being: Three decades of progress. Psychological Bulletin, 125(2), 276-302.

Diener, E. D., Emmons, R. A., Larsen, R. J., \& Griffin, S. (1985). The satisfaction with life scale. Journal of Personality Assessment, $49(1)$ ), $71-75$.

Doğan, T., \& ÇÖTOK, N. A. (2011). Adaptation of the short form of the oxford happiness questionnaire into Turkish: A validity and reliability study. Turkish Psychological Counseling and Guidance Journal, 4(36), 165-170.

Fellman, E. (2000). Power of positive thinking. B. Başak and S. Özçallı. Translated. Istanbul: Beyaz Publications.

George, D., \& Mallery, M. (2010). SPSS for windows step by step: A simple guide and Reference, 17.0 update (10th ed.). Boston: Pearson.

Gillham, J., \& Reivich, K. (2004). Cultivating optimism in childhood and adolescence. The Annals of the American Academy of Political and Social Science, 591(1), 146-163.Available at: https://doi.org/10.1177/0002716203260095.

Gülcan, A. (2014). Investigation of the effect of optimism on happiness and life satisfaction in young adults. Unpublished master's Thesis. Fatih University Institute of Social Sciences, Istanbul.

Güllü, S., \& Ciftçi, E. G. (2016). Investigation of the quality of life of individuals who are members of sports centers. International Journal of Social Sciences and Education Research, 2(3), 1251-1265.

Hills, P., \& Argyle, M. (2002). The oxford happiness questionnaire: A compact scale for the measurement of psychological well-being. Personality and Individual Differences, 33(7), 1073-1082.

Ho, M. Y., Cheung, F. M., \& Cheung, S. F. (2010). The role of meaning in life and optimism in promoting well-being. Personality and Individual Differences, 48(5), 658-663.

Karasar, N. (2013). Scientific research method (25th ed.). Ankara: Nobel Academic Publishing.

Kasatura, I. (1998). Personality and confidence. Istanbul: Evolution Publications.

Köker, S. (1991). Comparison of life satisfaction levels of normal and problem adolescents. Ankara University Institute of Social Sciences, Unpublished Master's Thesis, Ankara.

McGinnis, A. L. (1998). The power of optimism. A. Kayaş. Translate. Istanbul: White Publications.

Özkatar Kaya, E., Sarıtaş, N., Yıldız, K., \& Kaya, M. (2018). Research on physical activity and life satisfaction levels of sedentary and nonsedentary individuals. Celal Bayar University Journal of Health Sciences Institute, 5(3), 89-94.

Ryan, R. M., \& Deci, E. L. (2001). On happiness and human potentials: A review of research on hedonic and eudaimonic well-being. Annual Review of Psychology, 52(1), 141-166.

Sahin, Y. (2015). Investigation of the happiness, optimism and altruism levels of university students. Unpublished Master's Thesis. Gaziosmanpaşa University Institute of Educational Sciences, Tokat.

Sapmaz, F., \& Doğan, T. (2012). Examining the effect of optimism on happiness and life satisfaction. Mersin University Journal of Education Faculty, 8(3), 63-69.

Scheier, M., \& Carver, C. (1985). Optimism, coping, and health: Assessment and implications of generalized outcome expectancies. Health Psychology, 4(3), 2 19-247.

Seligman, M. E. P., \& Pawelski, J. O. (2003). Positive psychology: FAQs. Psychological Inquiry, 14(2), 159-163.

Tarhan, N. (2005). Psychology of happiness. Istanbul: Timaş Publications.

Vara, S. (1999). An investigation of job satisfaction and life satisfaction in intensive care unit' nurses. Unpublished Master Dissertation. Ege University, İzmir, Turkey.

Wike, H. K. (2015). Examining the relationship between physical activity, psychological well-being, and stress in a college population. Master Thesis. The University of Tennessee, Chattanooga. 